\title{
Enantioselective Olefin Epoxidation Using Novel Doubly Bridged Biphenyl Azepines as Catalysts
}

\author{
Roman Novikov, Jérôme Vachon, and Jérôme Lacour*
}

\begin{abstract}
Enantiopure (diastereomeric) doubly bridged biphenyl azepines prepared from (S)-3,3-dimethylbutan-2amine and (S)-1-phenylpropylamine can be - as a function of the exocyclic side chain - either effective catalysts for the enantioselective epoxidation of unfunctionalized olefins or no catalysts at all. In the case of the (S)-1-phenylpropylamine derivative, an unwanted and unexpected Cope elimination derails the catalytic reactivity which can, however, be recovered by the addition of NBS prior to that of the substrate and other reagents.
\end{abstract}

Keywords: Atropisomers · Catalysis · Chiral amines · Chirality · Cope Elimination · Epoxidation

\section{Introduction}

Chiral non-racemic epoxides are useful precursors in synthetic chemistry, and frequent structures in natural products, often related to their biological activity (Scheme 1). ${ }^{[1]}$ Quite a few efficient catalytic methods exist for their preparation from olefins and many of them are based on transition metals such as the Katsuki-Sharpless or Katsuki-Jacobsen protocols. ${ }^{[2]}$ In the recent years, much effort has been devoted to the development of organocatalyzed epoxidation conditions that afford metal-free procedures; the catalysts being perhydrate, dioxirane, oxaziridine, or oxoammonium moieties as well as ammonium or oxaziridinium salts. ${ }^{[3]}$

Oxaziridinium ions are attractive alternatives to the commonly-used dioxiranes. ${ }^{[4-8]}$ These organic salts are effective oxygen transfer reagents towards

\footnotetext{
${ }^{*}$ Correspondence: Prof. Dr. J. Lacour University of Geneva

Department of Chemistry

Quai Ernest-Ansermet 30

$\mathrm{CH}-1211$ Geneva 4

Fax: +4122 3793215

E-Mail: jerome.lacour@chiorg.unige.ch
}

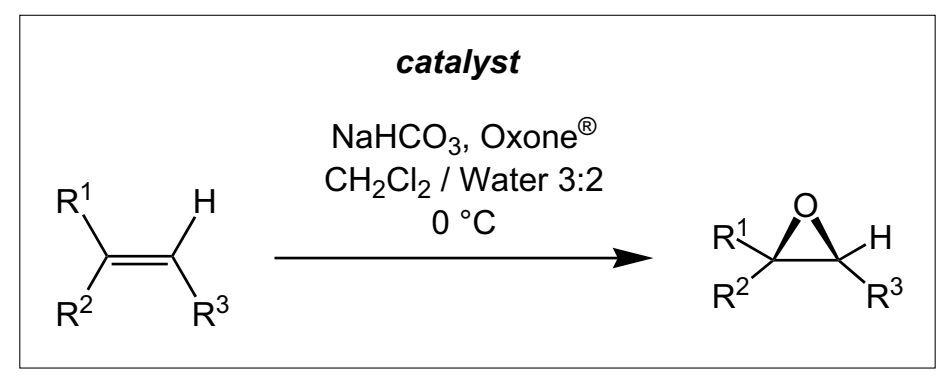

Scheme 1.

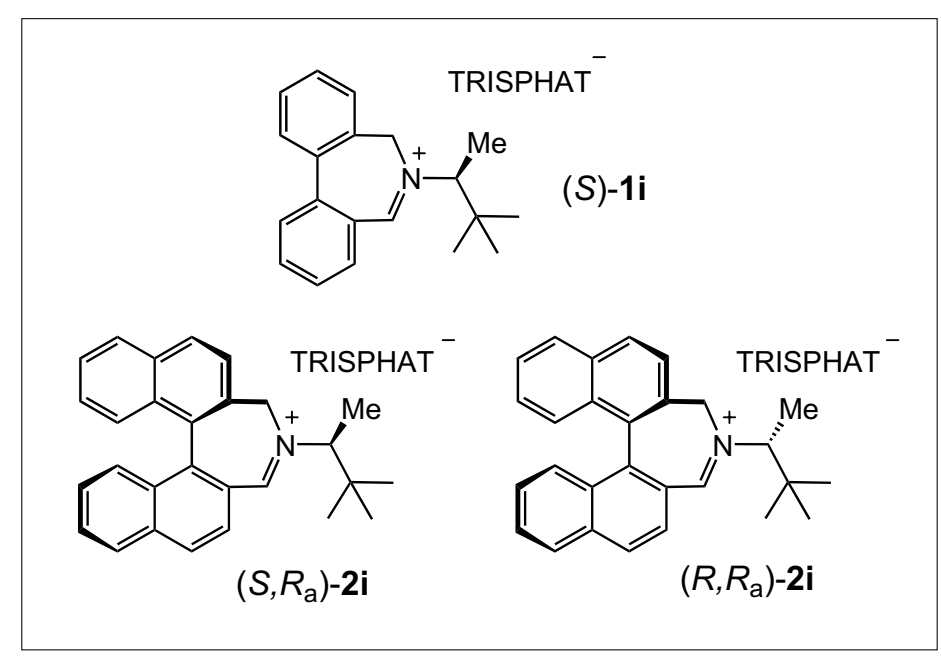

Fig. 1.

nucleophilic substrates and electron-rich unfunctionalized olefins in particular. Moreover, the propensity of iminium ions to react with Oxone ${ }^{\circledR}$ triple salt to generate the oxaziridinium species renders the development of catalytic processes possible. ${ }^{[9,10]}$ Several successful enantioselective variants of the reaction have been reported,[11-29] among which are studies using biphenyl 1i, ${ }^{[28]}$ and binaphthyl 2i iminium salts (Fig. 1). [29]

In compound $\mathbf{1 i}$, the stereocontrol over the reaction is provided by the exocyclic chiral appendage derived from enantiopure 3,3dimethylbutan-2-amine ( $S$ or $R$ enantiomer), which along with L-acetonamine, ${ }^{[18,20,22]}$ is 


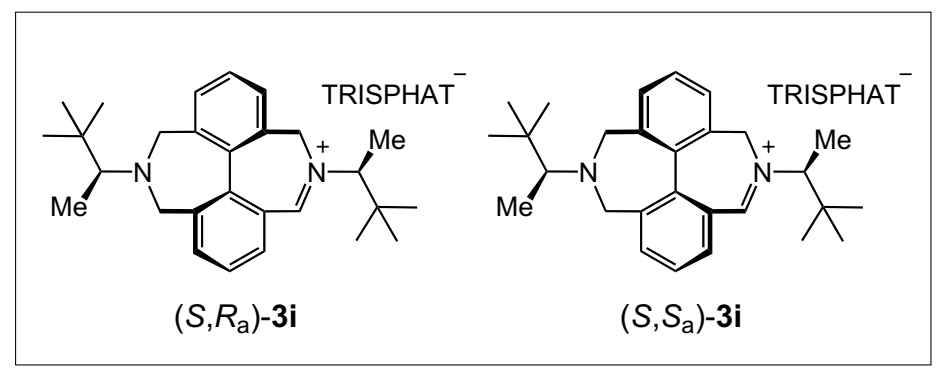

Fig. 2.

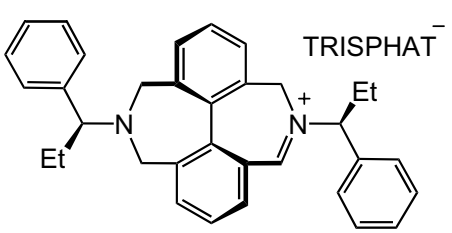

$\left(S, S_{\mathrm{a}}\right) \mathbf{- 4 i}$

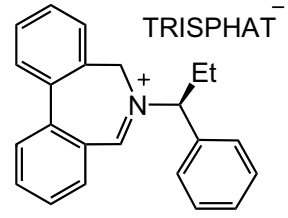

$(S)-5 i$
Fig. 3.

one of the best chiral auxiliary for this type of catalytic moiety.

Compounds $\left(S, R_{\mathrm{a}}\right)-\mathbf{2 i}$ and $\left(R, R_{\mathrm{a}}\right)-\mathbf{2} \mathbf{i}$ (Fig. 1) are diastereomers that incorporate both enantiopure 3,3-dimethylbutan-2amine ( $S$ or $R$ enantiomer) and a configurationally rigid binaphthyl core (here of $R$ configuration) as stereogenic elements. In this case, the atropos binaphthyl core has an overwhelming stereochemical influence. The enantioselectivity of the epoxidation reaction is controlled by the configuration of the biaryl moiety rather than the exocyclic appendage. ${ }^{[23,30]}$ Essentially identical $e e$ values are obtained in reactions of prochiral olefins in presence of diastereomeric $\left(S, R_{\mathrm{a}}\right)-\mathbf{2} \mathbf{i}$ and $\left(R, R_{\mathrm{a}}\right)-\mathbf{2 i}$ in favor of epoxides of identical configurations. [29] In these above-mentioned studies with $\mathbf{1 i}$ and $\mathbf{2 i}$, the counterion associated with the iminium ions has always been a TRISPHAT anion which, in the present case, only acts as a lipophilic genenion. ${ }^{[31-35]}$

Recently, in search for alternatives to the classical tropos biphenyl and atropos binaphthyl moieties, a series of iminium salts derived from atropos enantiopure diastereomeric doubly bridged biphenyl (DBB) azepines were tested as organocatalysts in the enantioselective epoxidation of prochiral olefins, and atropisomeric DBB iminium salts $\left(S, R_{\mathrm{a}}\right)-\mathbf{3 i}$ and $\left(S, S_{\mathrm{a}}\right)-3 \mathbf{i}$ in particular (Fig. 2). ${ }^{[36]}$ In sharp contrast with the atropos binaphthyl series (vide supra), the enantioselectivity of the epoxidation reaction is controlled by the configuration of the exocyclic appendage rather than that of the biaryl moiety. Somewhat different $e e$ values are obtained in reactions of prochiral olefins in presence of diastereomeric $\left(S, R_{\mathrm{a}}\right)$-3i and $\left(S, S_{\mathrm{a}}\right)-\mathbf{3 i}$, however always in favor of epoxides of identical configura-

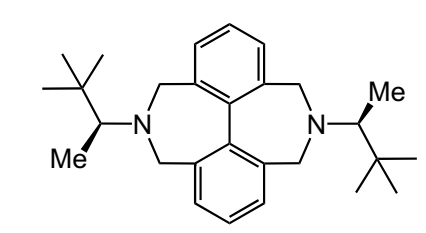

(S)-3a (2:1 mixture)

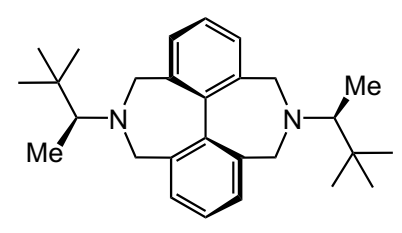

$\left(S, S_{a}\right)-3 a$

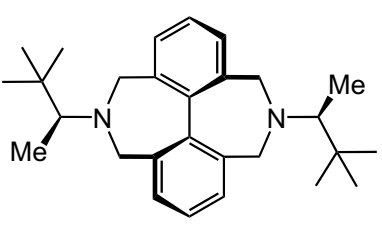

$\left(S, R_{\mathrm{a}}\right)-\mathbf{3 a}$

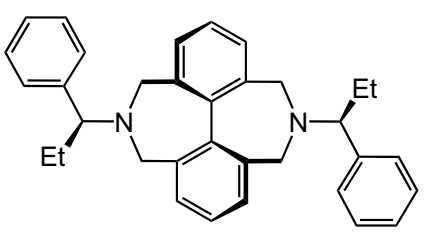

$\left(S, S_{a}\right)-\mathbf{4 a}$

Fig. 4.

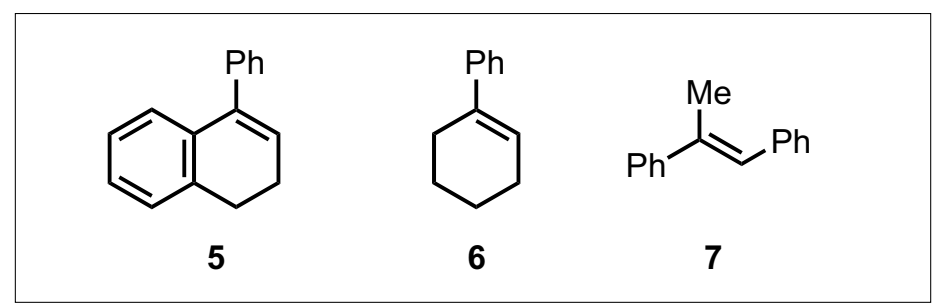

Fig. 5.

tions - the differences being assigned to moderate 'matched/mismatched' effects.

In this latter study, we showed that the central DBB core can also strongly enhance the stereochemical outcome of epoxidation reactions when the chiral exocyclic auxiliary fails to provide an effective stereoinduction by itself (in the tropos biphenyl series). It was particularly evident in the reactions performed with atropos $\mathrm{DBB}\left(S, S_{\mathrm{a}}\right)-\mathbf{4 i}$ and tropos $(S)-5 i$ (Fig. 3) derived from 'less effective' $(S)$-1-phenylpropylamine for which much better enantioselectivity could be achieved with $\operatorname{DBB}\left(S, S_{\mathrm{a}}\right)$-4i over $(S)$-biphenyl $\mathbf{5 i}$ (ee up to $85 \%$ vs. $35 \%$ ).

Finally and maybe more importantly, we have recently demonstrated that the saturated azepines precursors to the iminium ions $\mathbf{1 i}$ and $\mathbf{2 i}$ are essentially more effective catalysts for the enantioselective epoxidation of prochiral olefins than their unsaturated derivatives. ${ }^{[29,30]}$ As such, we wondered whether DBB azepines 3a and 4a (Fig. 4) would behave similarly and display also effective enantioselective oxidation abilities. Moreover, as the reactions of $\left(S, R_{\mathrm{a}}\right)-\mathbf{3 i}$ and $\left(S, S_{\mathrm{a}}\right)$-3i gave virtually the same results, we wondered if the diastereomeric mixture of $\left(S, R_{\mathrm{a}}\right)$-3a and $\left(S, S_{\mathrm{a}}\right)$-3a, namely $(S)$-3a obtained in two steps from pyrene $(2: 1 \mathrm{mix}-$ ture of atropisomers in favor of $\left.\left(S, R_{\mathrm{a}}\right)\right),{ }^{[36]}$ would be as effective a catalyst as the separated diastereomers; this allowing a rather tedious separation, $\left(S, R_{\mathrm{a}}\right)-\mathbf{3 a}$ and $\left(S, S_{\mathrm{a}}\right)-\mathbf{3 a}$, to be avoided.
Herein, we report that it is the case as the diastereomeric mixture of tertiary diamine $(S)$-3a derived from $(S)$-3,3-dimethylbutan2-amine is indeed an effective catalyst for the enantioselective epoxidation of unfunctionalized olefins. On the other hand, compound $\left(S, S_{\mathrm{a}}\right)$-4a (Fig. 4) derived from $(S)$-1phenylpropylamine and precursor to effective iminium catalyst $\left(S, S_{\mathrm{a}}\right)$-4i (Fig. 3 ) has absolutely no catalytic activity in presence of olefins and Oxone ${ }^{\circledR}$ triple salt by itself. Preliminary experiments allow an explanation to be postulated for this rather distinct reactivity behavior of $\mathbf{4 a}$, and also to find a simple solution to the problem.

\section{Results and Discussion}

\subsection{Epoxidation Reactions with DBB Azepines 3a Prepared from (S)-3,3-Dimethylbutan-2-amine}

The preparation of DBB azepines 3a and 4a has been previously reported. ${ }^{[36]}$ One set of epoxidation conditions (Oxone ${ }^{\circledR} / \mathrm{CH}_{2} \mathrm{Cl}_{2} / \mathrm{NaHCO}_{3} / 18$-crown- $6 / \mathrm{H}_{2} \mathrm{O}$ ) and three different prochiral trisubstituted unfunctionalized alkenes (5-7, Fig. 5) were selected for the study. The results are reported in Tables 1 and 2 .

Significantly, amine 3a acts as an effective catalyst for the enantioselective epoxidation of unfunctionalized olefins. Initial screening (Table 1) was performed with alkene $\mathbf{5}$ as a substrate and, as catalysts, the 
Table 1. Enantioselective epoxidation of olefin $\mathbf{5}$ using catalysts $(S)$-3a (mixture of diastereomers), and pure $\left(S, R_{\mathrm{a}}\right)-\mathbf{3 a}$ and $\left(S, S_{\mathrm{a}}\right)-\mathbf{3} \mathbf{a}^{\mathrm{a}}$

\begin{tabular}{|c|c|c|c|c|c|c|c|c|c|}
\hline \multirow[t]{2}{*}{ alkene } & \multicolumn{3}{|c|}{ (S)-3a (mixture) } & \multicolumn{3}{|c|}{ Amine $\left(S, R_{\mathrm{a}}\right)-\mathbf{3 a}$} & \multicolumn{3}{|c|}{ Amine $\left(S, S_{a}\right)-3 \mathbf{a}$} \\
\hline & $e e^{b}$ & Conv. & Conf. & $e e^{b}$ & Conv. & Conf. & $e e^{b}$ & Conv. & Conf. \\
\hline 5 & 75 & 98 & $(+)-(1 R, 2 S)$ & 77 & 55 & $(+)-(1 R, 2 S)$ & 79 & 69 & $(+)-(1 R, 2 S)$ \\
\hline
\end{tabular}

a5 mol \% of catalyst, $2.5 \mathrm{~mol} \% 18-\mathrm{C}-6,1.1$ equiv. Oxone ${ }^{\circledR}, 4.0$ equiv. $\mathrm{NaHCO}_{3}, \mathrm{CH}_{2} \mathrm{Cl}_{2} / \mathrm{H}_{2} \mathrm{O}(3: 2)$, $2 \mathrm{~h}, 0^{\circ} \mathrm{C}$. Average of at least two runs; bThe enantiomeric excesses were determined by CSPHPLC (5, CHIRALCEL-ODH, $0.5 \mathrm{ml} \cdot \mathrm{min}^{-1}$, hexane:i-PrOH 95:5, $\lambda 230 \mathrm{~nm}$ ); the conversions using an internal standard (naphthalene).

Table 2. Enantioselective epoxidation of olefins 5-7 using diastereomeric mixture of amine $(S)-\mathbf{3 a}$; $\left(S, R_{\mathrm{a}}\right)-\mathbf{3 i}$ and $\left(S, S_{\mathrm{a}}\right)-\mathbf{3 i}$ used as references ${ }^{\mathrm{a}}$

\begin{tabular}{|c|c|c|c|c|c|c|c|c|c|}
\hline \multirow[t]{2}{*}{ alkene } & \multicolumn{3}{|c|}{$(S)-3 \mathbf{a}$ (mixture) } & \multicolumn{3}{|c|}{$\left(S, R_{\mathrm{a}}\right)-\mathbf{3 i}$ (reference) } & \multicolumn{3}{|c|}{$\left(S, S_{a}\right)-3 \mathbf{i}$ (reference) } \\
\hline & $e e^{b}$ & Conv. & Conf. & $e e^{b}$ & Conv. & Conf. & $e e^{b}$ & Conv. & Conf. \\
\hline 5 & 75 & 98 & $(+)-(1 R, 2 S)$ & 76 & 80 & $(+)-(1 R, 2 S)$ & 49 & 76 & $(+)-(1 R, 2 S)$ \\
\hline 6 & 71 & 82 & $(-)-(1 S, 2 S)$ & 76 & 56 & $(-)-(1 S, 2 S)$ & $-c$ & $-c$ & $-c$ \\
\hline 7 & 45 & 46 & $(-)-(1 S, 2 S)$ & 59 & 61 & $(-)-(1 S, 2 S)$ & 41 & 75 & $(-)-(1 S, 2 S)$ \\
\hline
\end{tabular}

a5 mol \% of catalyst, $2.5 \mathrm{~mol} \% 18-\mathrm{C}-6,1.1$ equiv. Oxone ${ }^{\circledR}, 4.0$ equiv. $\mathrm{NaHCO}_{3}, \mathrm{CH}_{2} \mathrm{Cl}_{2} / \mathrm{H}_{2} \mathrm{O}(3: 2)$, $2 \mathrm{~h}, 0^{\circ} \mathrm{C}$. Average of at least two runs; bThe enantiomeric excesses were determined by CSP-GC (6. Chiraldex Hydrodex $\beta$-3P) or CSP-HPLC (5 and 7, CHIRALCEL-ODH, $0.5 \mathrm{ml} \cdot \mathrm{min}^{-1}$, hexane: $i$-PrOH 95:5, $\lambda 230 \mathrm{~nm}$ ); the conversions using an internal standard (naphthalene); ${ }^{c}$ experiment not performed.

Table 3. Enantioselective epoxidation of olefins 5-7 using $\left(S, S_{a}\right)-\mathbf{4 a}$ or $\left(S, S_{a}\right)-\mathbf{4 a}+N B S ;\left(S, S_{a}\right)-\mathbf{4 i}$ used as reference

\begin{tabular}{|c|c|c|c|c|c|c|c|c|c|}
\hline \multirow[t]{2}{*}{ alkene } & \multicolumn{3}{|c|}{ Amine $\left(S, S_{a}\right)-4 a^{a}$} & \multicolumn{3}{|c|}{$\left(S, S_{a}\right)-4 a+5$ mol\% NBS ${ }^{b}$} & \multicolumn{3}{|c|}{$\left(S, S_{a}\right)-4 i(\text { reference })^{a}$} \\
\hline & $e e^{c}$ & Conv. & Conf. & $e e^{c}$ & Conv. & Conf. & $e e^{c}$ & Conv. & Conf. \\
\hline 5 & - & 0 & - & 84 & 96 & $(-)-(1 S, 2 R)$ & 85 & 60 & $(-)-(1 S, 2 R)$ \\
\hline 6 & - & 0 & - & 73 & $85-94$ & $(+)-(1 R, 2 R)$ & 71 & 82 & $(+)-(1 R, 2 R)$ \\
\hline 7 & - & 0 & - & 41 & $33-43$ & $(+)-(1 R, 2 R)$ & 55 & 51 & $(+)-(1 R, 2 R)$ \\
\hline
\end{tabular}

a $5 \mathrm{~mol} \%$ of catalyst, $2.5 \mathrm{~mol} \% 18-\mathrm{C}-6,1.1$ equiv. Oxone ${ }^{\circledR}, 4.0$ equiv. $\mathrm{NaHCO}_{3}, \mathrm{CH}_{2} \mathrm{Cl}_{2} / \mathrm{H}_{2} \mathrm{O}(3: 2)$, $2 \mathrm{~h}, 0^{\circ} \mathrm{C}$. Average of at least two runs; ${ }^{\mathrm{b}} 5 \mathrm{~mol} \%$ of $4 \mathrm{a}+5 \mathrm{~mol} \%$ of $\mathrm{NBS}$ in $\mathrm{CH}_{2} \mathrm{Cl}_{2}$ added after 5 min to water (2:3 ratio to $\mathrm{CH}_{2} \mathrm{Cl}_{2}$ ), 2.5 mol \% 18-C-6, 1.1 equiv. Oxone ${ }^{\circledR}, 4.0$ equiv. $\mathrm{NaHCO}_{3}, 2 \mathrm{~h}$, $0{ }^{\circ} \mathrm{C}$. Average of at least two runs; ${ }^{\mathrm{C}}$ The enantiomeric excesses were determined by CSP-GC (6, Chiraldex Hydrodex $\beta$-3P) or CSP-HPLC (5 and 7, CHIRALCEL-ODH, $0.5 \mathrm{ml} \mathrm{min}^{-1}$, hexane:i-PrOH 95:5, $\lambda 230 \mathrm{~nm}$ ); the conversions using an internal standard (naphthalene).

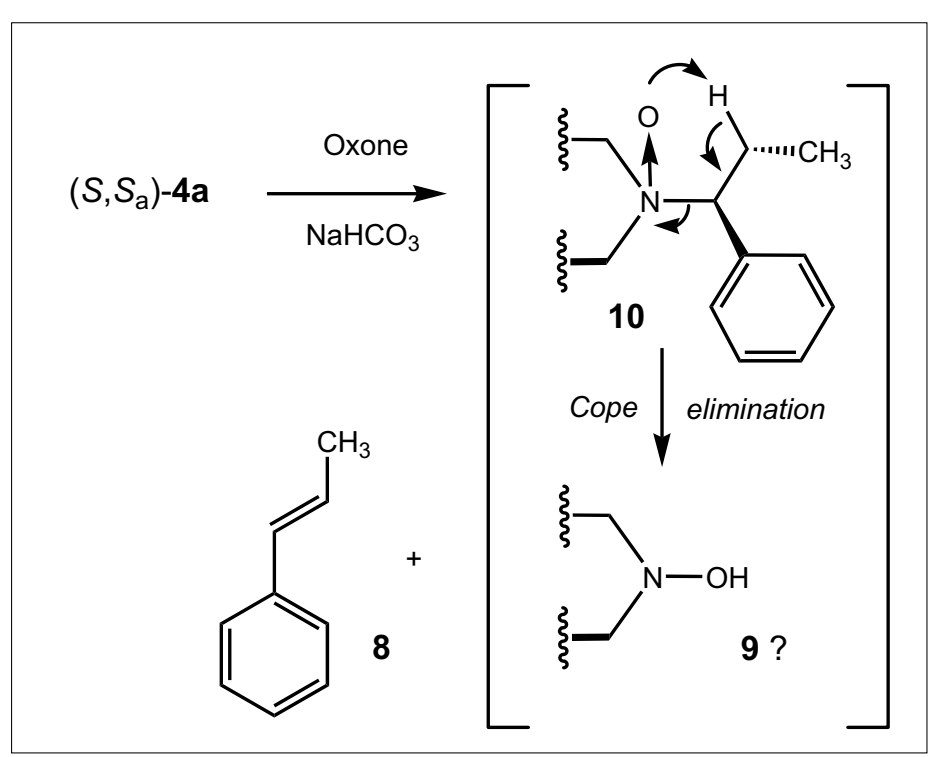

Scheme 2 simple-to-use mixture of atropisomers $(S)$ 3a or the separated diastereomers $\left(S, R_{\mathrm{a}}\right)-\mathbf{3 a}$ and $\left(S, S_{\mathrm{a}}\right)$-3a. As expected, it revealed very similar results for the three catalyst combinations. Whereas the enantioselectivity was slightly lower for the atropisomeric mixture (ee 75 vs. 77-79\%), the conversion was quite better.

With that result in hand, further reactions were performed with trivial mixture (S)-3a exclusively and compared to that of separated iminium salts $\left(S, R_{\mathrm{a}}\right)-\mathbf{3 i}$ and $\left(S, S_{\mathrm{a}}\right)$-3i (Table 2$)$. In terms of conversions, results were often better for the simple amine; enantiomeric excesses being alternatively at the higher or lower ends of the 'matched/mismatched' scale. On one hand, for olefin 5, an ee value of $75 \%$ was obtained that fits well with that obtained with matched catalyst $\left(S, R_{\mathrm{a}}\right)-3 \mathrm{i}$ (ee $\left.77 \%\right)$. On the other hand, for olefin 7 , the enantioselectivity reached only $45 \%$, barely above the value $(41 \%)$ obtained with the mismatched catalyst $\left(S, S_{\mathrm{a}}\right)-3 \mathbf{i}$. In any case, non-racemic epoxides of analogous absolute configurations were isolated from the reactions with amine 3a and iminium salts of $\left(S, R_{\mathrm{a}}\right)-\mathbf{3 i}$ and $\left(S, S_{\mathrm{a}}\right) \mathbf{- 3 i}$.

\section{2. (Lack of) Epoxidation Reactions with DBB Azepines Prepared from (S)-1-Phenylpropylamine}

Having confirmed with 3a that DBB azepines can be indeed as effective catalysts as their iminium derivatives for the enantioselective epoxidation of alkenes 5-7, an extension of this chemistry to $\mathrm{DBB}\left(S, S_{\mathrm{a}}\right) \mathbf{- 4 a}$ was looked for. However, in this case and to our surprise, no conversion could be detected ( ${ }^{1} \mathrm{H}$ NMR, GC, HPLC) in reactions performed in the presence of catalytic amounts of amine 4a (Table 3). Whereas the olefinic substrates remained unchanged in the crude reaction mixtures, diamine 4 a seemed to decompose. It was then our analysis that, under the reaction conditions, the particular DDB azepine 4a was transformed into unreactive material. Care was thus taken to treat, in the absence of any olefin, a substoichiometric $(5 \mathrm{~mol} \%)$ amount of $\left(S, S_{\mathrm{a}}\right)$ 4a with Oxone ${ }^{\circledR}$ (1.1 equiv.), $\mathrm{NaHCO}_{3}$ (4.0 equiv.) in $\mathrm{CH}_{2} \mathrm{Cl}_{2} / \mathrm{H}_{2} \mathrm{O}$ to identify the negative reaction pathway (Scheme 2 ). ${ }^{1} \mathrm{H}$ NMR spectroscopic analysis of the crude reaction mixture revealed the presence of unreacted diamine 4a along with some unexpected (E)-prop-1-enylbenzene 8 and an unknown reaction compound 9 .

At this stage, only a Cope elimination pathway can put forward to rationalize the formation of the conjugated olefin $\mathbf{8}$ that is obviously linked to the presence of the 1phenylpropanyl side chains of $\mathbf{4 a} .^{[37-42]}$ It is our proposal that, under the reaction conditions, DBB 4a is oxidized to a tertiary $\mathrm{N}$ oxide derivative 10. The oxygen atom then 
subsequently reacts intramolecularly with a $\beta$-hydrogen atom of the exocyclic side chain to yield olefin $\mathbf{8}$; compound 9 being possibly the resulting hydroxyl amine or a derivative of it.

In any case, no trace of iminium ion 4i can be observed in the crude reaction mixture of the above-mentioned reaction; the presence of iminium ions being easy to monitor by the appearance (or not) of singlet signals around $11.4 \mathrm{ppm}\left(\mathrm{CD}_{2} \mathrm{Cl}_{2}\right)$. To confirm this fact, $\left(S, S_{\mathrm{a}}\right)$-4a was treated with a stoichiometric amount of NBS in $\mathrm{CH}_{2} \mathrm{Cl}_{2}$ for $5 \mathrm{~min}$ and, as expected from previous studies, ${ }^{[29,30]}$ such a signal appeared predominantly on the NMR spectrum.

As such, epoxidation of prochiral unfunctionalized olefins can be performed with $\left(S, S_{\mathrm{a}}\right)-\mathbf{4 a}$ as precatalyst if care is taken to treat the DDB amine with NBS prior to the addition of other reagents and substrates. The results are summarized in Table 3. Not too surprisingly, virtually identical results are obtained using the mixture of $\mathbf{4 a}$ and NBS (5 mol\% each) instead of isolated iminium ion $\mathbf{4} \mathbf{i}$; only in the case of olefin 7 are the enantioselectivity and conversions lower if starting from the DDB azepine reagent directly.

\section{Conclusion}

To conclude, the 2:1 mixture of atropisomeric DBB azepines $\left(S, R_{\mathrm{a}}\right)-\mathbf{3 a}$ and $\left(S, S_{\mathrm{a}}\right)$ 3a performs essentially as well as the separated diastereomers or the derived iminium salts $\left(S, R_{\mathrm{a}}\right)$-3i and $\left(S, S_{\mathrm{a}}\right)$-3i as catalysts for the enantioselective epoxidation of some prochiral olefins. As using the DBB azepine mixture requires fewer synthetic and purification steps than the preparation of the diastereomerically pure iminium salts, it is therefore advantageous to use the trivial mixture for synthetic applications.

Investigations are currently underway to understand the mechanism of the catalytic process and track down the exact nature of the catalytic species.

\section{Typical Biphasic Enantioselective Epoxidation Procedure}

In a $10 \mathrm{ml}$ flask equipped with a magnetic stirring bar, $\mathrm{NaHCO}_{3}(67.0 \mathrm{mg}, 0.80 \mathrm{mmol}$, 4.0 equiv.) was added to $800 \mu$ l of water. Oxone ${ }^{\circledR}$ (132.0 mg, $0.21 \mathrm{mmol}, 1.0$ equiv.) was then added and the solution stirred for 2 min until effervescence subsided. $500 \mu$ l of a $0.4 \mathrm{~mol} / \mathrm{l}$ solution of the alkene $(0.20$ mmol, 1.0 equiv.) and naphthalene ( 0.20 mmol, 1.0 equiv., internal reference) in $\mathrm{CH}_{2} \mathrm{Cl}_{2}$ was added and the resulting biphasic mixture was cooled to $0{ }^{\circ} \mathrm{C}$ with an ice-bath. Catalyst 3a $(10.0 \mu \mathrm{mol}, 5 \mathrm{~mol} \%)$ in $\mathrm{CH}_{2} \mathrm{Cl}_{2}(500 \mu \mathrm{l})$ was added, followed by a solution of 18-crown-6 (1.0 mg, 5.0 $\mu \mathrm{mol}, 2.5 \mathrm{~mol} \%)$ in $\mathrm{CH}_{2} \mathrm{Cl}_{2}(200 \mu \mathrm{l})$. The reaction mixture was then stirred at $0{ }^{\circ} \mathrm{C}$ for $2 \mathrm{~h}$.

In the case of $\mathbf{4 a}$, the DBB azepine was treated with NBS $(5 \mathrm{~mol} \%$ ) for $5 \mathrm{~min}$ in $\mathrm{CH}_{2} \mathrm{Cl}_{2}(500 \mu \mathrm{l})$ prior to its addition to the aqueous layer.

\section{Acknowledgments}

We thank the University of Geneva, the Swiss National Science Foundation and the State Secretariat for Education and Science for support.

Received: March 21, 2007

[1] J. Marco-Contelles, M. T. Molina, S. Anjum, Chem. Rev. 2004, 104, 2857.

[2] 'Comprehensive Asymmetric Catalysis I-III', Eds. E. N. Jacobsen, A. Pfaltz, H. Yamamoto, Vol. 2, 1999.

[3] W. Adam, C. R. Saha-Moller, P. A. Ganeshpure, Chem. Rev. 2001, 101, 3499.

[4] P. Barbaro, C. Bianchini, Chemtracts 2001, 14, 274.

[5] W. Adam, C. R. Saha-Moeller, C.-G. Zhao, Org. React. 2002, 61, 219.

[6] X.-Y. Wu, X. She, Y. Shi, J. Am. Chem. Soc. 2002, 124, 8792.

[7] R. Curci, L. D'Accolti, C. Fusco, Acc. Chem. Res. 2006, 39, 1.

[8] D. Goeddel, L. Shu, Y. Yuan, O. A. Wong, B. Wang, Y. Shi, J. Org. Chem. 2006, 71, 1715.

[9] G. Hanquet, X. Lusinchi, P. Milliet, C. R. Acad. Sci., Ser. II: Mec., Phys., Chim., Sci. Terre Univers 1991, 313, 625.

[10] X. Lusinchi, G. Hanquet, Tetrahedron 1997, 53, 13727.

[11] L. Bohe, G. Hanquet, M. Lusinchi, X. Lusinchi, Tetrahedron Lett. 1993, 34, 7271.

[12] V. K. Aggarwal, M. F. Wang, Chem. Commun. 1996, 191.

[13] P. C. B. Page, G. A. Rassias, D. Bethell, M. B. Schilling, J. Org. Chem. 1998, 63, 2774.

[14] A. Armstrong, G. Ahmed, I. Garnett, K. Goacolou, J. S. Wailes, Tetrahedron 1999 , 55, 2341

[15] P. C. B. Page, G. A. Rassias, D. Barros, D. Bethell, M. B. Schilling, J. Chem. Soc., Perkin Trans. 1 2000, 3325.

[16] S. Minakata, A. Takemiya, K. Nakamura, I. Ryu, M. Komatsu, Synlett 2000, 1810.

[17] I. Washington, K. N. Houk, J. Am. Chem. Soc. 2000, 122, 2948.

[18] P. C. B. Page, G. A. Rassias, D. Barros, A. Ardakani, B. Buckley, D. Bethell, T. A. D. Smith, A. M. Z. Slawin, J. Org. Chem. 2001, 66, 6926.

[19] M.-K. Wong, L.-M. Ho, Y.-S. Zheng, C.-Y. Ho, D. Yang, Org. Lett. 2001, 3, 2587.

[20] P. C. B. Page, G. A. Rassias, D. Barros, A. Ardakani, D. Bethell, E. Merifield, Synlett 2002, 580 .
[21] J. Lacour, D. Monchaud, C. Marsol, Tetrahedron Lett. 2002, 43, 8257.

[22] P. C. B. Page, D. Barros, B. R. Buckley, A. Ardakani, B. A. Marples, J. Org. Chem. 2004, 69, 3595.

[23] P. C. B. Page, R. Buckley Benjamin, A. J. Blacker, Org. Lett. 2004, 6, 1543.

[24] P. C. B. Page, B. R. Buckley, H. Heaney, A. J. Blacker, Org. Lett. 2005, 7, 375.

[25] P. C. B. Page, D. Barros, B. R. Buckley, B. A. Marples, Tetrahedron: Asymmetry 2005, 16, 3488.

[26] P. C. B. Page, B. R. Buckley, G. A. Rassias, A. J. Blacker, Eur. J. Org. Chem. 2006, 803.

[27] P. C. B. Page, B. R. Buckley, D. Barros, A. J. Blacker, H. Heaney, B. A. Marples, Tetrahedron 2006, 62, 6607.

[28] J. Vachon, C. Pérollier, D. Monchaud, C. Marsol, K. Ditrich, J. Lacour, J. Org. Chem. 2005, 70, 5903.

[29] J. Vachon, C. Lauper, K. Ditrich, J. Lacour, Tetrahedron: Asymmetry 2006, 17, 2334.

[30] M.-H. Gonçalves, A. Martinez, S. Grass, P. C. B. Page, J. Lacour, Tetrahedron Lett. 2006, 47, 5297.

[31] J. Lacour, C. Ginglinger, C. Grivet, G. Bernardinelli, Angew. Chem., Int. Ed. Engl. 1997, 36, 608.

[32] F. Favarger, C. Goujon-Ginglinger, D. Monchaud, J. Lacour, J. Org. Chem. 2004, 69, 8521.

[33] J. Lacour, V. Hebbe-Viton, Chem. Soc. Rev. 2003, 32, 373.

[34] J. Lacour, R. Frantz, Org. Biomol. Chem. 2005, 3, 15.

[35] S. Constant, J. Lacour, Top. Curr. Chem. 2005, 250,1 .

[36] J. Vachon, S. Rentsch, A. Martinez, C. Marsol, J. Lacour, Org. Biomol. Chem. 2007, 5, 501 .

[37] B. M. Gallagher, W. H. Pearson, Chemtracts 1996, 9, 126.

[38] I. Hermecz, A. Szabo, G. Galambos, G. Timar, K. Simon, L. Vasvarine Debreczy, Z. Mucsi, Magy. Kem. Foly., Kem. Kozl. 2004, 109-110, 43.

[39] R. J. Griffin, A. Henderson, N. J. Curtin, A. Echalier, J. A. Endicott, I. R. Hardcastle, D. R. Newell, M. E. M. Noble, L.-Z. Wang, B. T. Golding, J. Am. Chem. Soc. 2006, 128,6012 .

[40] N. M. Garrido, D. Diez, S. H. Dominguez, M. Garcia, M. R. Sanchez, S. G. Davies, Tetrahedron: Asymmetry 2006, 17, 2183.

[41] N. Henry, I. A. O'Neil, Tetrahedron Lett. 2007, 48, 1691.

[42] G. L. Ellis, I. A. O’Neil, V. E. Ramos, S. B. Kalindjian, A. P. Chorlton, D. J. Tapolczay, Tetrahedron Lett. 2007, 48, 1687. 